\title{
Association between prevalence of anaemia and sedentary time among women.
}

\author{
Sang-Dol Kim*
}

Department of Nursing, College of Health Science, Kangwon National University, 346 Hwangjo-gil, Dogye-eup, Samcheok-si, Gangwon-do 25949, Republic of Korea

\begin{abstract}
This study aimed to assess the associations between prevalence of anaemia and sedentary time among women. Data of women aged $\geq 10 \mathrm{y}$ who were included in the $6^{\text {th }}$ Korea National Health and Nutrition Examination Survey (2014-2015) were analyzed $(n=3$, 593). Self-reported sedentary time was dichotomized into $\geq 7.5 \mathrm{~h} / \mathrm{d}$ or $<7.5 \mathrm{~h} / \mathrm{d}$. Sampling weights were generated based on the complex sample to ensure the representativeness of the sample to the Korean population. Logistic regression was used to identify the associations between prevalence of anaemia and sedentary time. The prevalence of anaemia among women aged $\geq 10 \mathrm{y}$ was $9.8 \%$. After adjusting for age, results showed that women with a prevalence of anaemia had a $31 \%$ lower odds of sitting for $\geq 7.5 \mathrm{~h} / \mathrm{d}$ (odds ratios (OR), 0.69; 95\% confidence interval (CI), 0.52-0.91) than those without prevalence of anaemia. Women aged between 10-14 y were 7.19 times (CI, 4.28-12.14) more likely to sit for $\geq 7.5 \mathrm{~h} / \mathrm{d}$ than those aged over $50 \mathrm{y}$. These findings imply that anaemia control in women aged 10-14 $\mathrm{y}$ is necessary to reduce excessive sedentary time.
\end{abstract}

Keywords: Anaemia, Sedentary time.

Accepted on May 03, 2018

\section{Introduction}

Sedentary behavior and increased sedentary time are crucial determinants of health outcomes [1]. Previous studies indicated that an overtly sedentary lifestyle could lead to various physical, psychosocial, and sociological problems globally $[1,2]$. Findings of previous studies stressed that reducing the excessive sedentary time is the focus of the interventions, and these interventions should be based on the clinical effects $[1,2]$. However, considering that sedentary behavior is defined as energy expenditure of $\leq 1.5$ metabolic equivalent of task (METS) in the waking state, avoiding sedentary behavior would require an individual to expend energy of $>1.5$ in their waking state [2,3]. In order to consume energy $>1.5$ METS, the required physical and physiological conditions must be met. Standing or activity behaviors need higher energy expenditure than sitting behavior [4]. A variety of physical activities have been applied to reduce the sedentary time [5]. However, the activity level should be evaluated based on the individual's health condition. The individuals must meet the required physical conditions to perform their activity. For example, light-intensity physical activity was effective in reducing the sedentary time of individuals with cardiovascular disease [6]. Anaemia is a risk factor for poorer exercise capacity [5]. Furthermore, excessive sitting time can increase cardiovascular disease risk $[7,8]$. Therefore, anaemia may lead to prolonged sedentary time among women due to several factors such as development of menstrual disorders and pregnancy $[9,10]$.
Hence, this study aimed to assess the associations between prevalence of anaemia and sedentary time among women.

\section{Materials and Methods}

In this study, data of women included in the $6^{\text {th }}$ Korea National Health and Nutrition Examination Survey (6th KNHANES; 2014-2015) were analyzed. The $6^{\text {th }}$ KNHANES was approved by the institutional review board of the KCDC (2013-07CON-03-4C and 2013-12EXP-03-5C) [11]. This study involved women aged $\geq 10 \mathrm{y}$ who participated in the $6^{\text {th }}$ KNHANES (2014-2015). Survey on sedentary time was conducted via self-reported interview using the following question: "how many hours do you usually sit or lie on a day?" The sedentary time was dichotomized into sitting $\leq 7.5 \mathrm{~h} / \mathrm{d}$ and sitting $>7.5 \mathrm{~h} / \mathrm{d}$; "this cut-off time was chosen based on a metaanalysis that suggested that the risk of all-cause mortality increases when women self-reported to sit approximately $>7-8$ $\mathrm{h} / \mathrm{d}$ " [12-14]. Haemoglobin test was measured using SLS haemoglobin detection method (2014: XE-2100D, Sysmex/ Japan; 2015: XN-9000, Sysmex/Japan). The following reagents were used in the test: Stromatolyser-FB, 4D1, IM, NR, Sulfolyser, Cellpack, Detergent, Cellclean Control, and eCheck (low/normal/high) (Sysmex/Japan). The prevalence of anaemia was calculated by dividing the number of women with haemoglobin $>11.0 \mathrm{~g} / \mathrm{dl}$ with the total number of women aged $\geq$ 10. Different haemoglobin levels were used to define patient's anaemia, depending on age and pregnancy status. Results 
showed that women aged 10-11 y had a haemoglobin level of $>11.5 \mathrm{~g} / \mathrm{dl}$, women aged $12-14 \mathrm{y}$ had $<12 \mathrm{~g} / \mathrm{dl}$, non-pregnant women aged $\geq 15 \mathrm{y}$ had $<12 \mathrm{~g} / \mathrm{dl}$, and pregnant women aged $\geq$ $15 \mathrm{y}$ had $<11.0(\mathrm{~g} / \mathrm{dl})$.

Statistical analyses were conducted using the SPSS program (version 18.0) for Windows. Sampling weights were generated based on the complex sample to ensure the representativeness of the sample to the Korean population. Logistic regression was used to determine the associations between prevalence of anaemia and sedentary time. Probability values of $<0.05$ were considered statistically significant.

\section{Results}

Variables are presented in Tables 1 and 2. The total number of women aged $\geq 10 \mathrm{y}$ was 3,593 , and the mean age was $43.85 \pm$ $0.56 \mathrm{y}$. Prevalence of anaemia among women aged over $10 \mathrm{y}$ was $9.8 \%$. After adjusting for age, results showed that women with prevalence of anaemia had a $31 \%$ lower odds of sitting for $\geq 7.5 \mathrm{~h} / \mathrm{d}(\mathrm{OR}, 0.69 ; \mathrm{CI}, 0.52-0.91)$ than those without anaemia. Women aged 10-14 y were 7.19 times (CI, 4.26-12.14) more and women aged 15-49 y were 1.79 times (CI, 1.53-2.09) more likely to sit for $\geq 7.5 \mathrm{~h} / \mathrm{d}$ than those women aged over $50 \mathrm{y}$.

Table 1. Characteristics among women $\geq$ aged $10(N=3,083)$.

\begin{tabular}{lll}
\hline Characteristics & $\mathbf{N}$ & \\
\cline { 2 - 3 } & $\%$ & SE (Standard Error) \\
\hline Age, mean & 43.85 & 0.56 \\
\hline Prevalence of anaemia & 9.8 & 0.6 \\
\hline Sedentary time, mean & 7.68 & 0.97 \\
\hline$<7.5$ h/d & 44.9 & 1.2 \\
\hline$\geq 7.5 \mathrm{~h} / \mathrm{d}$ & 55.1 & 1.2 \\
\hline
\end{tabular}

Table 2. Associations between prevalence of anaemia and sedentary time among women $\geq$ aged 10.

\begin{tabular}{llll}
\hline \multirow{4}{*}{ Characteristics } & \multicolumn{2}{l}{ Adjusted for age } & \\
\cline { 2 - 4 } & \multicolumn{2}{l}{ Sedentary time $\mathbf{7 . 5} \mathbf{~ h / d}$} & p value \\
\cline { 2 - 4 } & Weighted OR & $95 \% \mathbf{C l}$ & 0.008 \\
\hline Prevalence of anaemia & 0.69 & $0.52-0.91$ & \\
\hline Yes & 1 & Reference & \\
\hline No & & & 0 \\
\hline 41913 & 7.19 & $4.26-12.14$ & \\
\hline $15-49$ & 1.79 & $1.53-2.09$ & 0 \\
\hline $50+$ & 1 & Reference & \\
\hline
\end{tabular}

\section{Discussion}

As shown in the study results, prevalence of anaemia among women aged over $10 \mathrm{y}$ was $9.8 \%$. These findings support that anaemia occurs more frequently in adolescents and women of reproductive age $[9,10]$. After adjusting for age, results showed that women with prevalence of anaemia had $31 \%$ lower odds of sitting for $\geq 7 \mathrm{~h} / \mathrm{d}$ than those without anaemia. In particular, women aged 10-14 y and 15-49 y seemed to be vulnerable to too much sitting time. Therefore, women aged 10-14 y are at risk of developing anaemia, while women aged of 15-49 y are at risk of developing menstrual disorders and pregnancyrelated disorders. These results are similar to the previous study showing that adolescents' sitting behavior is negatively associated with cardiovascular disease [14]. Therefore, the findings imply that a targeted intervention to reduce and regularly interrupt the sitting time of adolescents and women of reproductive age is required. So far, the relationship between prevalence of anaemia and sedentary time were explored minimally. To the best of our knowledge, this is the first study to evaluate the association between prevalence of anaemia and sedentary time. However, the causes of anaemia were not identified in this study. Hence, future studies should be conducted to identify these causes and appropriate measures should be taken.

\section{Conclusion}

In conclusion, prevalence of anaemia was significantly associated with sedentary time among women with anaemia. Importantly, anaemia control in women aged 10-14 $\mathrm{y}$ is necessary to reduce excessive sedentary time.

\section{Acknowledgement}

Data of this study were obtained from the $6^{\text {th }}$ Korea National Health and Nutrition Examination Survey (2015) conducted by the Korea Centers for Disease Control and Prevention.

\section{References}

1. Copeland JL, Ashe MC, Biddle SJ, Brown WJ, Buman MP, Chastin S, Gardiner PA, Inoue S, Jefferis BJ, Oka K, Owen N, Sardinha LB, Skelton DA, Sugiyama T, Dogra S. Sedentary time in older adults: a critical review of measurement, associations with health, and interventions. Br J Sports Med 2017; 51: 1539-1547.

2. Dogra S, Ashe MC, Biddle SJH, Brown WJ, Buman MP, Chastin S, Gardiner PA, Inoue S, Jefferis BJ, Oka K, Owen N, Sardinha LB, Skelton DA, Sugiyama T, Copeland JL. Sedentary time in older men and women: an international consensus statement and research priorities. Br J Sports Med 2017; 51: 1526-1532.

3. Sedentary Behavior Research Network. Letter to the editor: standard use of the terms "sedentary" and 
"sedentary behaviours". Appl Physiol Nutr Metab 2012; 37: 540-542.

4. Campbell SDI, Brosnan BJ, Chu AKY, Skeaff CM, Rehrer NJ, Perry TL, Peddie MC. Sedentary behavior and body weight and composition in adults: a systematic review and meta-analysis of prospective studies. Sports Med 2018; 48: 585-595.

5. Ekegren CL, Beck B, Climie RE, Owen N, Dunstan DW, Gabbe BJ. Physical activity and sedentary behavior subsequent to serious orthopedic injury: A systematic review. Arch Phys Med Rehabil 2018; 99: 164-177.

6. Dohrn IM, Kwak L, Oja P, Sjöström M, Hagströmer M. Replacing sedentary time with physical activity: a 15-year follow-up of mortality in a national cohort. Clin Epidemiol 2018; 10: 179-186.

7. Bellettiere J, Winkler EAH, Chastin SFM, Kerr J, Owen N, Dunstan DW, Healy GN. Associations of sitting accumulation patterns with cardio-metabolic risk biomarkers in Australian adults. PLoS One. 2017; 12: e0180119.

8. Ferrari M, Manea L, Anton K, Bruzzone P, Meneghello M, Zamboni F, Purgato L, Cazzoletti L, Ferrari P, Testi R. Anemia and hemoglobin serum levels are associated with exercise capacity and quality of life in chronic obstructive pulmonary disease. BMC Pulm Med 2015; 15: 58.

9. Ndiaye NF, Idohou-Dossou N, Diouf A, Guiro AT, Wade S. Individual and community factors contributing to anemia among women in rural Baja California, Mexico. Food Nutr Bull 2018; 39: 65-74.

10. Mchiza ZJ, Parker WA, Sewpaul R, Job N, Chola L, Mutyambizi C, Sithole M, Stokes A, Labadarios D. Understanding the determinants of hemoglobin and iron status: adolescent-adult women comparisons in SANHANES-1. Ann N Y Acad Sci 2018.

11. Korea Centers for Disease Control and Prevention. The 6th Korea national health and nutrition examination survey. Centers Dis Control Prev 2015.

12. Chau JY, Grunseit AC, Chey T, Stamatakis E, Brown WJ, Matthews CE, Bauman AE, van der Ploeg HP. Daily sitting time and all-cause mortality: a meta-analysis. PLos One 2013; 8: 1-14.

13. Lakerveld J, Loyen A, Schotman N, Peeters CFW, Cardon G, van der Ploeg HP, Lien N, Chastin S, Brug J. Sitting too much: A hierarchy of socio-demographic correlates. Prev Med 2017; 101: 77-83.

14. Hinckson E, Cerin E, Mavoa S, Smith M, Badland H, Stewart T, Duncan S, Schofield G. Associations of the perceived and objective neighborhood environment with physical activity and sedentary time in New Zealand adolescents. Int J Behav Nutr Phys Act 2017; 14: 145.

\section{*Correspondence to}

Sang-Dol Kim

Department of Nursing

College of Health Science

Kangwon National University

346 Hwangjo-gil

Gangwon-do 25949

Republic of Korea 